a Local General Arrangements Committee has been formed consisting of representatives of the Royal Ministry of the Interior, the Imperial Board of Health, the City of Berlin, the Medical Officers of The Head-Quarter Staffs of The Army and Navy, the University of Berlin, the Medical and Hygienic Societies of Berlin, etc., to promote the success of the meeting.

I am desired by the Council to invite the Medico-Psychological Association to appoint one or more representatives to attend the meeting.

1. The Congress will be under the Presidency of The Right Hon. the Earl Beauchamp, K.C.M.G., LL.D., His Majesty's First Commissioner of Works, and will be conducted in the following Sections :

A. State Medicine.-President: Sir T. Clifford Allbutt, K.C.B., M.D., LL.D., D.Sc., F.R.S., Regius Professor of Medicine in the University of Cambridge.

B. Bacteriology and Comparative Pathology.-President: Professor G. Sims Woodhead, M.A., M.D., LL.D., F.R.S.Ed., Professor of Pathology in the University of Cambridge.

c. Child Study and School Hygiene-President: Sir James Crichton-Browne, M.D., D.Sc., LL.D., F.R.S., Lord Chancellor's Visitor in Lunacy.

D. Military, Colonial and Naval. - President : Major Sir Ronald Ross, K.C.B., M.D., D.Sc., F.R.S., Professor of Tropical Medicine in the University of Liverpool.

E. Municipal Engineering, Architecture and Town Planning.-President: P. C. Cowan, D.Sc., M.Inst.C.E., Chief Engineer of the Local Government Board, Ireland.

The various Congress and Sectional Officers will also include gentlemen of German nationality occupying distinguished scientific and municipal positions.

Facilities will also be afforded for visiting the various Public Health and Educational Institutions in Berlin, etc., in connection with the Imperial Board of Health, the Municipality, the University, etc., and it is confidently hoped that the Congress and the unique opportunities which will thus be given to representatives of universities, learned bodies, county councils, municipalities, and other authorities of the United Kingdom, for becoming practically acquainted with continental institutions and their work, will not only be of much interest, but of the greatest value.

Arrangements are being made for travelling and hotel accommodation at reduced charges.

In order to facilitate the arrangements which must necessarily be made, I shall be obliged if you will kindly return enclosed form at your earliest convenience.

I am, Your obedient Servant,

\title{
JAMES CANTLIE,
}

Hon. Secretary.

\section{THE LIBRARY OF THE MEDICO-PSYCHOLOGICAL ASSOCIATION.}

The Library is open daily for reading, and for the purpose of borrowing books. Books may also be borrowed by post, provided that at the time of application threepence in stamps is forwarded to defray the cost of postage. Arrangements have been made with Messrs. Lewis to enable the Association to obtain books from the lending library belonging to that firm should any desired book not be in the Association's Library.

The following books have recently been added to the Library:

McDougall.-Body and Mind.

Angell.-Psychology.

Application for books should be addressed to the Resident Librarian, MedicoPsychological Association, II, Chandos Street, Cavendish Square, W. Other communications should be addressed to the undersigned at Long-Grove Asylum, Epsom.

Bernard Hart 